\title{
Succinispira mobilis gen. nov., sp. nov., a succinate-decarboxylating anaerobic bacterium
}

\author{
Peter H. Janssen and Katrina A. O'Farrell \\ Author for correspondence: Peter H. Janssen. Tel: +6139344 5706. Fax: +61393471540. \\ e-mail: p.janssen@microbiology.unimelb.edu.au
}

Department of Microbiology and Immunology, University of Melbourne, Parkville, Victoria 3052, Australia

\begin{abstract}
A succinate-decarboxylating anaerobic bacterium, designated strain 19gly ${ }^{\top}$, was previously isolated from a mixed culture growing with glycolate. The almost complete sequence of the 165 rRNA gene (1495 nt) was determined for this strain. On the basis of 165 rRNA gene sequence homology, strain 19gly ${ }^{\top}$ was identified as a member of the Sporomusa sub-branch of the 'low G+C' Gram-positive bacteria. Phylogenetic analysis showed that strain $19 \mathrm{gly} 1^{\top}$ was most closely related to Succiniclasticum ruminis, Phascolarctobacterium faecium and Acidaminococcus fermentans. The use of different algorithms, such as least-squares or neighbour-joining analyses of Jukes-Cantor pairwise distances, or maximum-parsimony or maximum-likelihood analyses of the aligned sequence data, revealed that strain $19 \mathrm{gly}^{1}$ grouped as the most deeply branching lineage of the strain 19gly1'-SucciniclasticumAcidaminococcus-Phascolarctobacterium cluster. The phenotypic characteristics of strain $19 \mathrm{gly} 1^{\top}$ distinguish it from members of the genera Succiniclasticum, Phascolarctobacterium and Acidaminococcus, and the phylogenetic distances inferred from comparative analysis of the 165 rDNA sequences suggest that strain $19 \mathrm{gly} 1^{\top}$ is a representative of a new genus. Accordingly, strain $19 \mathrm{gly}^{\top}$ ( $=$ DSM $6222^{\top}$ ) is proposed as the type strain of a new species within a new genus, Succinispira mobilis gen. nov., sp. nov.
\end{abstract}

Keywords: Succinispira mobilis, Gram-positive anaerobe, succinate decarboxylation, 16S rRNA gene

\section{INTRODUCTION}

Propionigenium modestum was the first strictly anaerobic bacterium unequivocally shown to be able to grow by coupling the decarboxylation of succinate to the generation of ATP (Schink \& Pfennig, 1982). Propionigenium modestum and the related Propionigenium maris (Janssen \& Liesack, 1995) belong to cluster XIX (Collins et al., 1994) of the 'low $\mathrm{G}+\mathrm{C}^{\prime}$ Gram-positive bacteria (Clostridium spp. and relatives) and are related to Fusobacterium spp. A succinate-decarboxylating Peptostreptococcus sp. (Janssen et al., 1996) was found to belong to cluster XIII (Collins et al., 1994) of the 'low G+C' Grampositive bacteria. However, the majority of the bacterial species known to be able to grow anaerobically on succinate by a decarboxylation reaction, yielding

Abbreviation: ANGIS, Australian National Genomic Information Service. The EMBL accession number for the 165 rRNA gene sequence of strain $19 \mathrm{gly} 1^{\top}$ is AJ006980. propionate and $\mathrm{CO}_{2}$ (or $\mathrm{HCO}_{3}^{-}$), belong to the Sporomusa sub-branch of the 'low $\mathrm{G}+\mathrm{C}$ ' Grampositive bacteria, corresponding to cluster IX of Collins et al. (1994). These include Schwartzia succinivorans (van Gylswyk et al., 1997), Selenomonas acidaminovorans (Guangsheng et al., 1992), Sporomusa acidovorans (Ollivier et al., 1985), Sporomusa termitida (Breznak et al., 1988), Sporomusa malonica (Dehning et al., 1989) and Succiniclasticum ruminis (van Gyslwyk, 1995). The ability to decarboxylate succinate is also found in other members of the Sporomusa subbranch such as Veillonella parvula, which can couple succinate decarboxylation to ATP synthesis (Janssen, 1992), Selemononas ruminantium (Scheifinger \& Wolin, 1973) and Phascolarctobacterium faecium (Osawa et al., 1992).

A succinate-decarboxylating anaerobic bacterium, designated strain $19 \mathrm{glyl}^{\mathrm{T}}$, was isolated from a mixed culture growing with glycolate (Janssen, 1990, 1991). This strain was clearly able to grow with succinate and a possible sodium-dependent succinate metabolism 
was found (Janssen, 1991). The strain was characterized phenotypically, but could not be assigned to a known genus. Possible affiliations with Campylobacter-like organisms have been discussed, but evidence for inclusion of this strain within the genus Campylobacter was unconvincing (Janssen, 1991). We have now used comparative 16S rRNA gene sequence analysis to help classify strain $19 \mathrm{gly} 1^{\mathrm{T}}$.

\section{METHODS}

Strain and growth conditions. Strain $19 \mathrm{gly} 1^{\mathrm{T}}\left(=\mathrm{DSM} 6222^{\mathrm{T}}\right)$ was obtained from the Deutsche Sammlung von Mikroorganismen und Zellkulturen. Cultures were grown in the freshwater medium FM of Janssen et al. (1997) with $20 \mathrm{mM}$ succinate and $1 \mathrm{~g}$ yeast extract $1^{-1}$ in completely filled screwcapped bottles, at $30^{\circ} \mathrm{C}$.

DNA extraction. Late exponential-phase cultures were harvested by centrifugation and the cells were washed in TE buffer $(10 \mathrm{mM}$ Tris, $1 \mathrm{mM}$ EDTA, $\mathrm{pH} 8$ with $\mathrm{HCl})$. Cell pellets were resuspended in $3.5 \mathrm{ml}$ E3T buffer $[50 \mathrm{mM}$ EDTA, $50 \mathrm{mM}$ Tris, $0.5 \%(\mathrm{w} / \mathrm{v})$ Tween $20,0.5 \%(\mathrm{w} / \mathrm{v})$ Triton $\mathrm{X}-100, \mathrm{pH} 8.0$ with $\mathrm{NaOH}$ and $0.7 \mathrm{mg}$ RNase A (Qiagen), $8 \mathrm{mg}$ lysozyme (Fluka) and $2 \mathrm{mg}$ protease (Qiagen) were added. After $30 \mathrm{~min}$ incubation at $37^{\circ} \mathrm{C}, 1.2 \mathrm{ml} \mathrm{GT}$ buffer [ $3 \mathrm{M}$ guanidine. $\mathrm{HCl}, 20 \%(\mathrm{w} / \mathrm{v})$ Tween 20 , pH 5.5 with $\mathrm{NaOH}$ ] was added, followed by further incubation at $50{ }^{\circ} \mathrm{C}$ for $15 \mathrm{~min}$. The preparations were cooled to room temperature, $0 \cdot 1$ vol. $5 \mathrm{M} \mathrm{NaCl}$ and 2 vol. $100 \%$ ethanol were added and mixed well, and the preparations were incubated at $-20^{\circ} \mathrm{C}$ for $2 \mathrm{~h}$. Genomic DNA was collected by centrifugation at $3000 \mathrm{~g}$ and $4^{\circ} \mathrm{C}$ for $20 \mathrm{~min}$, air-dried at room temperature, then dissolved in $1 \mathrm{ml}$ TE buffer. Phenol $(1 \mathrm{ml}$ ) equilibrated to $\mathrm{pH} 8.0$ (Sigma) was added, and the two phases were mixed by briefly vortexing. The two phases were then separated by centrifugation at $13000 \mathrm{~g}$ for $5 \mathrm{~min}$, and the aqueous phase was extracted with an equal volume of phenol:chloroform: isoamyl alcohol ( $25: 24: 1$, by vol.), and then with an equal volume of chloroform:isoamyl alcohol $(24: 1, \mathrm{v} / \mathrm{v})$. The extracted DNA was precipitated after the addition of 0.1 vol. $5 \mathrm{M} \mathrm{NaCl}$ and 2 vol. $100 \%$ ethanol, washed once in $70 \%$ ethanol, and the DNA pellet was dissolved in $50 \mu \mathrm{TE}$ buffer after being air-dried.

165 rRNA gene sequence determination. The almost complete 16S rRNA gene was amplified by PCR using the oligonucleotide primers $27 \mathrm{f}$ and $1525 \mathrm{r}$ (Lane, 1991) in a Progene thermocycler (Techne). The reaction mix $(100 \mu \mathrm{l}$ final volume) contained $10 \mathrm{mM}$ Tris $/ \mathrm{HCl}\left(\mathrm{pH} 9.0\right.$ at $\left.25^{\circ} \mathrm{C}\right)$, $50 \mathrm{mM} \mathrm{KCl}, 1 \mathrm{mM} \mathrm{MgCl}, 0 \cdot 1 \%$ (w/v) Triton X-100, $20 \mu \mathrm{g}$ BSA, $0.2 \mathrm{mM}$ each of dATP, dCTP, dGTP and dTTP, 100 pmol of each primer (Beckman Instruments) and about $250 \mathrm{ng}$ extracted genomic DNA. The thermal profile for PCR was as follows: (i) $94{ }^{\circ} \mathrm{C}$ for 4 min, after which $2.5 \mathrm{U}$ Taq DNA polymerase (Promega) was added to each reaction, followed by a further $60 \mathrm{~s}$ at $94^{\circ} \mathrm{C}$, then (ii) 35 cycles of $56^{\circ} \mathrm{C}$ for $90 \mathrm{~s}, 72^{\circ} \mathrm{C}$ for $120 \mathrm{~s}$ and $94^{\circ} \mathrm{C}$ for $60 \mathrm{~s}$, followed by (iii) 1 cycle of $56^{\circ} \mathrm{C}$ for $90 \mathrm{~s}$ and $72{ }^{\circ} \mathrm{C}$ for $6 \mathrm{~min}$. The PCR product was purified by gel electrophoresis $(1 \%$ low-melting point agarose; Progen) and the bands were excised after staining with ethidium bromide and visualization under UV light. The excised gel fragments were heated to $65^{\circ} \mathrm{C}$ and TE buffer was added to give a total volume of $400 \mu \mathrm{l}$. Phenol $(400 \mu \mathrm{l}, \mathrm{pH} 8.0)$ was added and the two phases were mixed by briefly vortexing. The two phases were then separated by centrifugation at $13000 \mathrm{~g}$ for $5 \mathrm{~min}$, and the aqueous phases were extracted with an equal volume

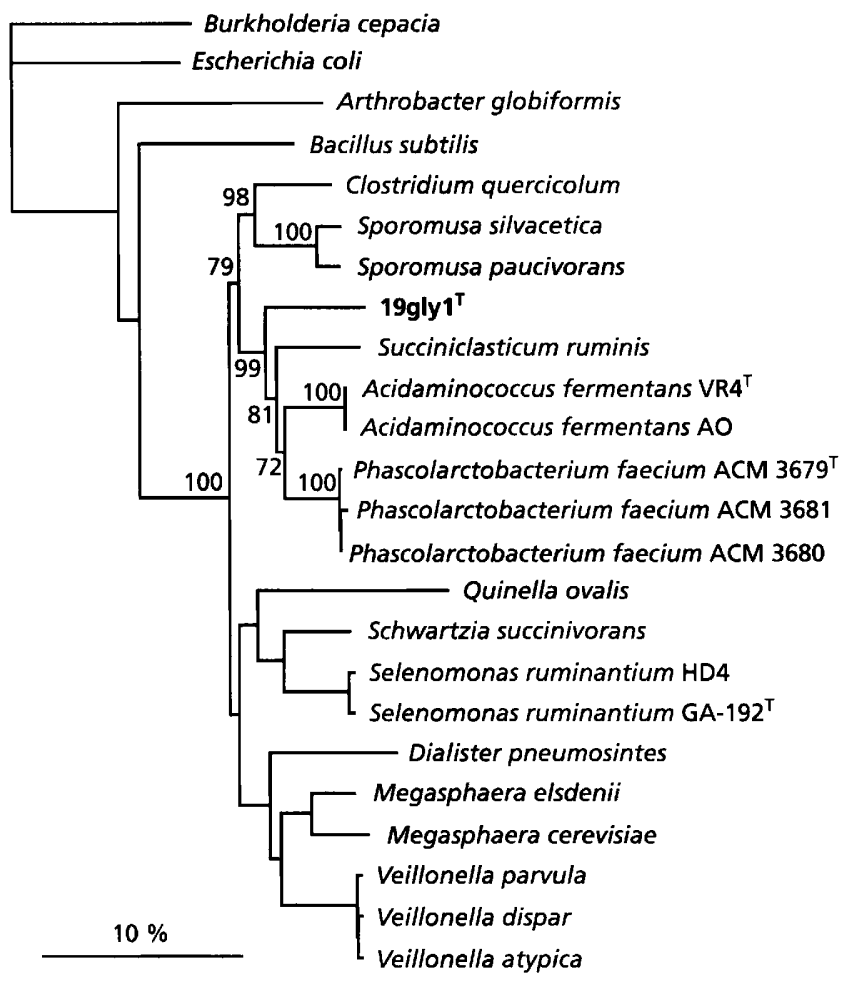

Fig. 1. Phylogenetic dendrogram indicating the relationships between strain $19 \mathrm{gly} 1^{\top}$ and other members of the Sporomusa sub-branch of the 'low $G+C$ ' Gram-positive bacteria. The dendrogram is based on 16S rRNA gene sequences and was derived from pairwise evolutionary distances by the leastsquares method. Scale bar, 10 inferred nucleotide substitutions per 100 nucleotides. Numbers given at the nodes represent bootstrap percentage values (1000 analyses; not all are shown).

of phenol:chloroform:isoamyl alcohol (25:24:1, by vol.), and then with an equal volume of chloroform:isoamyl alcohol $(24: 1, \mathrm{v} / \mathrm{v})$. Ammonium acetate $(10 \mathrm{M}, 100 \mu \mathrm{l})$ and $1 \mathrm{ml} 100 \%$ ethanol were then added to the aqueous phase which was incubated at $-20^{\circ} \mathrm{C}$ for $16 \mathrm{~h}$. The samples were then centrifuged at $13000 \mathrm{~g}$ for $15 \mathrm{~min}$ at $4{ }^{\circ} \mathrm{C}$ and the resultant pellet was washed by adding $500 \mu 170 \%$ ethanol and centrifuging again. The pellet, consisting of the PCR product, was then air-dried. The purified PCR product was sequenced by using ABI PRISM Dye Terminator technology (Applied Biosystems) at the Australian Genome Research Facility at the Walter and Eliza Hall Institute of Medical Research (Parkville, Victoria, Australia). The sequencing oligonucleotide primers were $27 \mathrm{f}, 519 \mathrm{r}, 530 \mathrm{f}, 907 \mathrm{r}, 926 \mathrm{f}$ and 1525r (Lane, 1991). The data were assembled and edited using the software package SEQUENCHER version 3.1RC4 (Gene Codes Corporation).

Comparative sequence analysis. The almost complete $16 \mathrm{~S}$ rRNA gene sequence was compared with known 16S rRNA gene sequences by carrying out a BLAST search (Altschul et al., 1990) in the GenBank database (Benson et al., 1997). The 16S rRNA gene sequence of strain $19 \mathrm{glyl}^{\mathrm{T}}$ was then aligned against homologous sequences of selected members (see Fig. 1) of cluster IX (Collins et al., 1994) obtained from GenBank using the alignment program PILEUP implemented in the ANGIS (Australian National Genomic Information Service) system (Littlejohn et al., 1996). This alignment was 
then manually checked and corrected, and regions of uncertain alignment were eliminated, using the 16S rRNA eubacterial mask of Lane (1991) as a guide, with the software SEQAPP version 1.9a169 (D. G. Gilbert, Biology Department, Indiana University, Bloomington, IN, USA). Further analyses were restricted to the unambiguously aligned regions totalling 1232 positions corresponding to nucleotide positions 101-205, 220-452, 481-859, 862-1000, 1037-1127, 1145-1262 and 1265-1431 of the Escherichia coli 16S rRNA gene (numbering according to Brosius et al., 1978).

Evolutionary analyses were carried out using the Wisconsin Package version 8.1.0 (Genetics Computer Group, Madison, WI, USA) and the EGCG package (Peter Rice, Sanger Centre, Cambridge, UK), implemented in the ANGIS system. Evolutionary distances between pairs of micro-organisms were determined using the Jukes \& Cantor (1969) equation implemented in the EDNADIST program and a tree estimating the phylogenetic relationships was derived using the EFITCH program of the same package employing a least-squares algorithm (Fitch \& Margoliash, 1967), with a random-order input of sequences and the global rearrangement option. Trees were represented graphically using the software TREEVIEWPPC version 1.4 (R. D. M. Page, Division of Environmental \& Evolutionary Biology, University of Glasgow, Glasgow, UK). The significance of the nodes was tested by bootstrap analysis generating evolutionary distances and using neighbour-joining to produce 1000 trees, and then compiling a consensus tree, using the programs ESEQBOOT, EDNADIST, ENEIGHBOR and ECONSENSE. MaXimumlikelihood and maximum-parsimony analyses of the sequence data and neighbour-joining analysis of the evolutionary distances employed the programs EDNAML, EDNAPARS and ENEIGHBOR, respectively.

Nucleotide sequence accession numbers. The GenBank accession numbers for sequences used as references in phylogenetic analyses are as follows: Acidaminococcus fermentans AO, X77951; Acidaminococcus fermentans VR4 ${ }^{\mathrm{T}}$, X78017; Arthrobacter globiformis, M23411; Bacillus subtilis, X60646; Burkholderia cepacia, M22518; Clostridium quercicolum, M59110; Dialister pneumosintes, X82500; Escherichia coli, J01695; Megasphaera cerevisiae, L37040; Megasphaera elsdenii, M26493; Phascolarctobacterium faecium ACM $3679^{\mathrm{T}}$, X72865; Phascolarctobacterium faecium ACM 3680 , X72867; Phascolarctobacterium faecium ACM 3681, X72866; Quinella ovalis, M62701; Schwartzia succinivorans, Y09434; Selenomonas ruminantium GA-192 ${ }^{\mathrm{T}}$, M62702; Selenomonas ruminantium HD4, M62703; Sporomusa paucivorans, M59117; Sporomusa silvacetica, Y09976; Succiniclasticum ruminis, X81137; Veillonella atypica, X84007; Veillonella dispar, X84006; and Veillonella parvula, $\mathrm{X} 84005$.

\section{RESULTS AND DISCUSSION}

\section{Phylogenetic analysis}

An almost complete 16S rRNA gene sequence $(1495 \mathrm{nt})$ was determined for strain $19 \mathrm{glyl}^{\mathrm{T}}$. A BLAST search revealed that the sequence of the 16S rRNA gene of strain $19 \mathrm{gly} 1^{\mathrm{T}}$ was most similar to those of various members of the Sporomusa sub-branch of the 'low $\mathrm{G}+\mathrm{C}$ ' Gram-positive bacteria, corresponding to cluster IX of Collins et al. (1994). The cell wall structure of strain $19 \mathrm{gly} 1^{\mathrm{T}}$ was found to be of a Gram-negative type with an outer membrane (Janssen, 1991), con- sistent with that of other members of the Sporomusa sub-branch of the 'low G +C' Gram-positive bacteria, which also have Gram-negative cell wall types, despite belonging to a lineage of the Gram-positive bacteria (Woese, 1987).

A comparison with representatives of this group by comparative analysis of the primary sequence of their $16 \mathrm{~S}$ rRNA genes (Fig. 1) shows that strain $19 \mathrm{glyl}^{\mathrm{T}}$ is most closely related to Succiniclasticum ruminis (van Gylswyk, 1995), Phascolarctobacterium faecium (Del Dot et al., 1993) and Acidaminococcus fermentans (Rogosa, 1984; Cook et al., 1994). The use of different algorithms, such as least-squares or neighbour-joining analyses of Jukes-Cantor pairwise distances, or maximum-parsimony or maximum-likelihood analyses of the aligned sequence data, revealed that the overall topologies of the trees varied slightly. Leastsquares and neighbour-joining methods yielded the same tree topologies. Maximum-parsimony and maximum-likelihood analyses grouped the Clostridium quercicolum-Sporomusa spp. cluster as a sister group of the Veillonella-Megasphaera-Selenomonas cluster, which is reflected in the low bootstrap value (79\%) of the branching point between the $19 \mathrm{glyl}^{\mathrm{T}}-$ Succiniclasticum - Acidaminococcus - Phascolarctobacterium and the Clostridium quercicolum-Sporomusa spp. clusters.

In all the analyses, strain $19 \mathrm{gly} 1^{\mathrm{T}}$ grouped as the most deeply branching lineage of the $19 \mathrm{glyl}^{\mathrm{T}}-$ Succiniclasticum - Acidaminococcus - Phascolarctobacterium cluster. Bootstrap analysis shows that the branching order is not certain, and so the exact evolutionary relationship of strain $19 \mathrm{glyl}^{\mathrm{T}}$ with the genera Succiniclasticum, Acidaminococcus and Phascolarctobacterium remains unresolved. The $16 \mathrm{~S}$ rRNA gene sequence similarities between strain $19 \mathrm{glyl}^{\mathrm{T}}$ and its relatives, based on the $1231 \mathrm{nt}$ positions examined, are $88.8 \%$ to Succiniclasticum ruminis, $90.9-91.2 \%$ to Phascolarctobacterium faecium strains and $91.2 \%$ to Acidaminococcus fermentans strains.

\section{Comparison with related taxa}

The phenotypic characteristics of strain $19 \mathrm{glyl}{ }^{\mathrm{T}}$ (Janssen, 1991) distinguish it from members of the genera Succiniclasticum, Phascolarctobacterium and Acidaminococcus (Table 1). The phylogenetic distances inferred from the 16S rRNA gene sequences, together with the phenotypic differences, suggest that strain $19 \mathrm{glyl}^{\mathrm{T}}$ is a representative of a new genus distinct from Succiniclasticum, Phascolarctobacterium and Acidaminococcus. Accordingly, we propose strain $19 \mathrm{glyl}^{\mathrm{T}}\left(=\mathrm{DSM} 6222^{\mathrm{T}}\right.$ ) as the type strain of a new species within a new genus, Succinispira mobilis gen. nov., sp. nov. Since there is only one strain available in pure culture, we describe the genus, species and strain together here, realising that further strains and species will allow a definition of specific and generic characteristics. The phenotypic characteristics are based on a previous study (Janssen, 1991). 
Table 1. Comparison of phenotypic characteristics of strain $19 \mathrm{gly} 1^{\top}$ and members of the species Succiniclasticum ruminis, Phascolarctobacterium faecium and Acidaminococcus fermentans

Data from Rogosa (1984), Janssen (1991), Osawa et al. (1992), Del Dot et al. (1993), Cook et al. (1994), van Gylswyk (1995). +, Positive; $(+)$, stimulates growth; -, negative; w, weak growth by some strains; ND, no data.

\begin{tabular}{|lcccc|}
\hline Characteristic & 19gly1 & $\begin{array}{c}\text { Succiniclasticum } \\
\text { ruminis }\end{array}$ & $\begin{array}{c}\text { Phascolarctobacterium } \\
\text { faecium }\end{array}$ & $\begin{array}{c}\text { Acidaminococcus } \\
\text { fermentans }\end{array}$ \\
\hline Cell shape & Curved rod & Short rod & Pleomorphic rod \\
Motility & + & - & - & Coccus \\
G+C (mol \%) & 36 & 52 & $41-42$ & - \\
Propionate production & + & + & + & - \\
Growth with: & + & + & - & - \\
$\quad$ Succinate & - & - & $\mathrm{ND}$ \\
Carbohydrates & + & - & $\mathrm{W}$ \\
Amino acids & & & + \\
\hline
\end{tabular}

\section{Description of Succinispira gen. nov.}

Succinispira [Suc.ci.ni.spi'ra. L. n. succinum amber; M.L. n. acidum succinicum succinic acid (derived from amber); Gr. n. spira coil, spiral; M.L. fem. n. Succinispira succinate-utilizing, spiral-shaped bacterium].

The type species is Succinispira mobilis. The genus and species descriptions are combined below until further species are described.

\section{Description of Succinispira mobilis sp. nov.}

Succinispira mobilis (mo'bi.lis. L. adj. mobilis movable, motile).

The cells are curved rods, $0.5 \mu \mathrm{m}$ in diameter and $2-10 \mu \mathrm{m}$ long. Longer cells can be spirals of up to 3 or 4 turns with an amplitude of $1.5-2.0 \mu \mathrm{m}$ and a wavelength of 3-4 $\mu \mathrm{m}$. Endospores are not formed. The cells are highly motile with laterally inserted flagella. Cytochromes are not formed. Gram-staining gives a negative result. Aminopeptidase activity is absent and the cell wall structure appears to be of a Gram-negative type with an outer membrane. Colonies in agar-deep cultures are white and lens-shaped. Liquid cultures grow with a uniform turbidity. The genomic DNA has a $\mathrm{G}+\mathrm{C}$ ratio of $36 \mathrm{~mol} \%$, determined by thermal denaturation. Comparative analysis of the 16S rRNA gene suggests a close phylogenetic relationship with the genera Succiniclasticum, Phascolarctobacterium and Acidaminococcus within the Sporomusa sub-branch of the 'low $\mathrm{G}+\mathrm{C}$ ' Gram-positive bacteria. The species displays a chemo-organotrophic fermentative metabolism. Pyruvate, citrate, oxaloacetate, maleate, succinate, fumarate, glutamate and aspartate are fermented, whereas carbohydrates and alcohols are not utilized. Formate, acetate, propionate, malate, $\mathrm{CO}_{2}$ and $\mathrm{H}_{2}$ are the fermentation end-products, depending on the substrate. Hydrogenase activity is present. Sulfate, sulfur, thiosulfate, nitrate and fumarate are not used as terminal electron acceptors. Aesculin hydrolysis, urea hydrolysis, indole formation from L-tryptophan and sulfide formation from $\mathrm{L}$-cysteine are all negative. The organism is a strict anaerobe. Media containing a suitable reductant are required for growth. Growth factors are required and can be supplied by the addition of yeast extract. The range of $\mathrm{pH}$ for growth is $6 \cdot 7-8 \cdot 5$, with an optimum of $7 \cdot 4-7 \cdot 7$. The optimum growth temperature is $37^{\circ} \mathrm{C}$. No growth is possible at $40{ }^{\circ} \mathrm{C}$. NaCl at $0.2 \mathrm{~g} \mathrm{l}^{-1}$ is sufficient for growth. Growth is possible at $\mathrm{NaCl}$ concentration of $19 \mathrm{~g}^{-1}$, but not at $24 \mathrm{~g}^{-1}$. The type strain, $19 \mathrm{glyl}^{\mathrm{T}}$ (= DSM $6222^{\mathrm{T}}$ ), was isolated from a mixed culture growing on glycolate, originally obtained from a pond receiving effluent from an anaerobic solids digester.

\section{REFERENCES}

Altschul, S. F., Gish, W., Miller, W., Myers, E. W. \& Lipman, D. J. (1990). Basic local alignment search tool. $J$ Mol Biol 215, 403-410.

Benson, D. A., Boguski, M. S., Lipman, D. J. \& Ostell, J. (1997). GenBank. Nucleic Acids Res 25, 1-6.

Breznak, J. A., Switzer, J. M. \& Seitz, H. J. (1988). Sporomusa termitida sp. nov., an $\mathrm{H}_{2} / \mathrm{CO}_{2}$-utilizing acetogen isolated from termites. Arch Microbiol 150, 282-288.

Brosius, J., Palmer, M. L., Kennedy, P. J. \& Noller, H. F. (1978). Complete nucleotide sequence of the 16S ribosomal RNA gene from Escherichia coli. Proc Natl Acad Sci USA 75, 4801-4805.

Collins, M. D., Lawson, P. A., Willems, A., Cordoba, J. J., Fernandez-Garayzabal, J., Garcia, P., Cai, J., Hippe, H. \& Farrow, J. A. E. (1994). The phylogeny of the genus Clostridium: proposal of five new genera and eleven new species combinations. Int $J$ Syst Bacteriol 44, 812-826.

Cook, G. M., Rainey, F. A., Chen, G., Stackebrandt, E. \& Russell, J. B. (1994). Emendation of the description of Acidaminococcus 
fermentans, a trans-aconitate- and citrate-oxidizing bacterium. Int J Syst Bacteriol 44, 576-578.

Dehning, I., Stieb, M. \& Schink, B. (1989). Sporomusa malonica sp. nov., a homoacetogenic bacterium growing by decarboxylation of malonate or succinate. Arch Microbiol 151, 421-426.

Del Dot, T., Osawa, R. \& Stackebrandt, E. (1993). Phascolarctobacterium faecium gen. nov., spec. nov., a novel taxon of the Sporomusa group of Bacteria. Syst Appl Microbiol 16, 380-384.

Fitch, W. M. \& Margoliash, E. (1967). Construction of phylogenetic trees. Science 155, 279-284.

Guangsheng, C., Plugge, C. M., Roelofsen, W., Houwen, F. P. \& Stams, A. J. M. (1992). Selenomonas acidaminovorans sp. nov., a versatile thermophilic proton-reducing anaerobe able to grow by decarboxylation of succinate to propionate. Arch Microbiol 157, 169-175.

van Gylswyk, N. O. (1995). Succiniclasticum ruminis gen. nov., sp. nov., a ruminal bacterium converting succinate to propionate as the sole energy-yielding mechanism. Int $J$ Syst Bacteriol 45, 297-300.

van Gylswyk, N. O., Hippe, H. \& Rainey, F. A. (1997). Schwartzia succinivorans gen. nov., sp. nov., another ruminal bacterium utilizing succinate as the sole energy source. Int J Syst Bacteriol 47, 155-159.

Janssen, P. H. (1990). Fermentation of glycollate by a mixed culture of anaerobic bacteria. Syst Appl Microbiol 13, 327-332.

Janssen, P. H. (1991). Characterization of a succinate-fermenting anaerobic bacterium isolated from a glycolate-degrading mixed culture. Arch Microbiol 155, 288-293.

Janssen, P. H. (1992). Growth yield increase and ATP formation linked to succinate decarboxylation in Veillonella parvula. Arch Microbiol 157, 442-445.

Janssen, P. H. \& Liesack, W. (1995). Succinate decarboxylation by Propionigenium maris sp. nov., a new anaerobic bacterium from an estuarine sediment. Arch Microbiol 165, 29-35.

Janssen, P. H., Liesack, W., Kluge, C., Seeliger, S., Schink, B. \& Harfoot, C. G. (1996). Sodium-dependent succinate decarboxyl- ation by a new anaerobic bacterium belonging to the genus Peptostreptococcus. Antonie Leeuwenhoek 70, 11-20.

Janssen, P. H., Schuhmann، A., Mörschel, E. \& Rainey, F. A. (1997). Novel anaerobic ultramicrobacteria belonging to the Verrucomicrobiales lineage of bacterial descent isolated by dilution culture from anoxic rice paddy soil. Appl Environ Microbiol 63, 1382-1388.

Jukes, T. H. \& Cantor, C. R. (1969). Evolution of protein molecules. In Mammalian Protein Metabolism, vol. 3, pp. 21-132. Edited by H. N. Munro. New York: Academic Press.

Lane, D. J. (1991). 16S/23S rRNA sequencing. In Nucleic Acid Techniques in Bacterial Systematics, pp. 115-175. Edited by E. Stackebrandt \& M. Goodfellow. Chichester: Wiley.

Littlejohn, T. G., Bucholtz, C. A., Campbell, R. M. M., Gaëta, B. A., Huynh, C. \& Kim, S. H. (1996). Computing for biotechnology WebANGIS. Australas Biotechnol 6, 211-217.

Ollivier, B., Cord-Ruwisch, R., Lombardo, A. \& Garcia, J. L. (1985). Isolation and characterization of Sporomusa acidovorans $\mathrm{sp}$. nov., a methylotrophic homoacetogenic bacterium. Arch Microbiol 142, 307-310.

Osawa, R., Fujisawa, T. \& Mitsuoka, T. (1992). Characterization of Gram-negative anaerobic strains, isolated from koala feces, which exhibit satellite growth and pleomorphism. Syst Appl Microbiol 15, 628-635.

Rogosa, M. (1984). Acidaminococcus. In Bergey's Manual of Systematic Bacteriology, vol. 1, p. 684. Edited by N. R. Krieg \& J. G. Holt. Baltimore: Williams \& Wilkins.

Scheifinger, C. C. \& Wolin, M. J. (1973). Propionate formation from cellulose and soluble sugars by combined cultures of Bacteroides succinogenes and Selenomonas ruminantium. Appl Microbiol 26, 789-795.

Schink, B. \& Pfennig, N. (1982). Propionigenium modestum gen. nov., sp. nov., a new strictly anaerobic, nonsporing bacterium growing on succinate. Arch Microbiol 133, 209-216.

Woese, C. R. (1987). Bacterial evolution. Microbiol Rev 51, 221-271. 